\title{
Distribution and Indexation of Plant Available Nutrients of District Layyah, Punjab Pakistan
}

\author{
Muhammad Ashraf ${ }^{1}$, Fayyaz Ahmad Tahir ${ }^{1}$, Muhammad Nasir², Muhammad Bilal Khan ${ }^{3, *}$, \\ Farah Umer ${ }^{1}$
}

${ }^{1}$ Soil and Water Testing Laboratory Layyah, Punjab Pakistan

${ }^{2}$ Soil and Water Testing Laboratory Multan, Punjab Pakistan

${ }^{3}$ Soil and Water Testing Laboratory Muzaffar Garh, Punjab Pakistan

Email address:

bilalkhan_arid@yahoo.com (M. B. Khan)

\section{To cite this article:}

Muhammad Ashraf, Fayyaz Ahmad Tahir, Muhammad Nasir, Muhammad Bilal Khan, Farah Umer. Distribution and Indexation of Plant Available Nutrients of District Layyah, Punjab Pakistan. American Journal of Agriculture and Forestry. Vol. 3, No. 2, 2015 , pp. 16-20. doi: 10.11648/j.ajaf.20150302.11

\begin{abstract}
During last five years 2008-09 to 2012-13, a study was conducted to assess the fertility and salinity/sodicity status of district Layyah for the provision of guidelines to farmers and researchers for better crop production. Representative soil samples received/collected from farmers' fields were analyzed for texture, electrical conductivity (EC), $\mathrm{pH}$, organic matter (O.M) and available phosphorus (P). A total of 31032 soil samples were collected from all tehsils of Layyah district, (15768 samples from tehsil Layyah, 7650 from Karor Lal Eisen, and 7614 from Chaubara). These soil samples were tested in Soil and Water Testing Laboratory Layyah and fertilizer recommendations were served to farmers according to soil and crop. The results showed that, soil texture of $91.18 \%$ soil samples was sandy loam (light), $8.53 \%$ loam (medium) and $0.29 \%$ clayey (heavy). About $99.42 \%$ soil samples had EC values within the normal range $\left(<4 \mathrm{dS} \mathrm{m}^{-1}\right)$ while $0.68 \%$ had $\left(>4 \mathrm{dS} \mathrm{m}^{-1}\right)$. The $\mathrm{pH}$ of $88.43 \%$ soil samples was up to 8.5 whereas $11.57 \%$ had $>8.5$. Organic matter content of $94.20 \%$ soil sample was poor $(<0.86 \%), 5.25 \%$ medium $(0.86-1.29 \%)$ and only $0.55 \%$ adequate $(>1.29 \%)$. Available phosphorus of $67.75 \%$ soil sample was poor, $\left(<7 \mathrm{mg} \mathrm{kg}^{-1}\right), 25.00 \%$ medium $\left(7.1-14 \mathrm{mg} \mathrm{kg}^{-1}\right)$ while only $7.25 \%$ adequate $\left(>14 \mathrm{mg} \mathrm{kg}^{-1}\right)$. Awareness camps, rallies and training programmes can be arranged for farmers regarding the benefits of soil and water testing, balanced use of chemical fertilizers and use of organic agriculture in crop production in improving soil fertility and nutrition status.
\end{abstract}

Keywords: Soil analysis, EC, pH, OM, P, Layyah, Nutrient Index

\section{Introduction}

Land is a basic unit, which is used to perform human activities like forestry, horticulture and agriculture. In the biotic ecological meaning land is the source of global biodiversity by specifying biological territory and genetic material for vegetation, flora and fauna and micro-organisms, above and below Land (FAO, 1997). Relating to water a healthy soil can perform a number of vital functions like store water and nutrients, helps to regulate water flow, and neutralize all kinds of pollutants. Soil production capacity is limited and these limits are laid down by intrinsic characteristics, agro-ecological settings, apply and management (FAO, 1993).

Historically, mainly the enlargement of the various civilizations flourished in the Middle East was dictating by the accessibility of fertile soil and water. Continuous cropping was only feasible where the soils were rich in nutrients or fertility was regenerated through flood-borne sediments. While these days the main constraint to grow crops is inadequate moisture, due to limited water supplies and erratic rainfall, economic crop production is not feasible without an adequate supply of the fundamental nutrients, either from the soil or added as fertilizers. During the past three four decades, when chemical fertilizers began to be used extensively, has established the essential need of fertilizer nitrogen $\mathrm{N}$ in all regions specially in drought stressed areas. Likely, the calcareous nature of most soils in the region such that phosphorus $\mathrm{P}$ fertility is low, and thus without added $\mathrm{P}$ fertilizer sufficient crop yields are not possible. Fortunately, other important crop growth nutrients such as potassium, magnesium, calcium, and sulfur are well 
supplied in less fertile soils (J. Ryan, 2004).

Most of the soils in Pakistan have poor status of available plant nutrients and cannot support optimum levels of crop productivity (Rafiq, 1996; Ahmed and Rashid, 2003). The primary objective of soil testing is to help making soil test based fertilizer use recommendations. It helps in applying different nutrients in balanced ratio so as to get maximum efficiency of the applied fertilizers and profitable crop production (Motsara, 2002). Soil test measure some fraction of total supply of nutrients in the soil and indicate its available nutrient level. The higher soil test values mean higher level of nutrients and thus the lower will be the need for fertilization and vise-versa. There is a network of Soil and Water Testing Laboratories in the country to provide advisory service to farmers on soil and water management (Ahmed and Rashid, 2003).

The Layyah District has an extremely hot climate. Maximum temperature in the summer goes up to 53 Degree Celsius. The temperature in winter is low due to the area's nearness to Koh-Suleman range of mountains. The Chaubara Tehsil is almost barren and consists of forest and sand dunes. It lies between 30-45 to 31-24 degree north latitudes and 7044 to 71-50 degree east longitudes. The area consists of a semi-rectangular block of sandy land between the Indus and Chenab rivers in Sindh Sagar Doaba. The tehsils of Layyah and Karor Lal Esan are developed agriculturally compared to other tehsils of the distract but still have are large tracks of sand dunes and uncultivated land. The Indus River passes from north to south on the western side of the district and touches Dera Ghazi Khan. Cotton, wheat, sugarcane, gram, watermelon, citrus and green chilly is the main agricultural product of district Layyah. The main objective of this study was to compile information on soil fertility and soil salinity/ sodicity status of district Layyah on the basis of soil samples analyzed during the last five years 2008-2013.

\section{Material and Methods}

This study was conducted in Soil and Water Testing Laboratory,Layyah, Pakistan during 2008-2013. A total of 31032 soil samples were collected from all tehsils of Layyah district, (15768 samples from tehsil Layyah, 7650 from Karor Lal Eisen, and 7614 from Chaubara). These samples were collected from 0-15 and 15-30 cm depths for crops and vegetables while $0-15,15-30,30-60,60-90,90-120$ and 120$150 \mathrm{~cm}$ depths for fruit plants and orchards. Samples were air-dried, ground and passed through a $2 \mathrm{~mm}$ sieve and analysed for physical and chemical properties. Soil texture was determined by measuring saturation percentage of soils (Malik et al., 1984), electrical conductivity (EC) by preparing 1:10 soil and water suspension (Soil Salinity Lab. Staff, 1954), pH (Schofield and Taylor, 1955), organic matter (Nelson and Sommers, 1982), available P (Olsen and Sommers, 1982) and K (Helmke and Sparks, 1996). The data were subjected to statistical analysis using MS Excel 2007 package. The criteria used for the classification is given in Table 1 as described by Malik et al 1984 .
Table 1. Criteria of parameters used for classification.

(a) Soil texture

\begin{tabular}{ll}
\hline Saturation percentage & Textural class \\
\hline $0-20$ & Sand \\
$21-30$ & Sandy loam \\
$31-45$ & Loam \\
$46-65$ & Clay loam \\
$65-100$ & Clay \\
\hline
\end{tabular}

(b) Soil salinity/sodicity

\begin{tabular}{lll}
\hline Status & $\mathbf{p H}$ & $\mathbf{E C}(\mathbf{d S} / \mathbf{m})$ \\
\hline Normal (salts free) & $<8.5$ & $<4$ \\
Saline & $<8.5$ & $>4$ \\
Saline sodic & $>8.5$ & $>4$ \\
Sodic & $>8.5$ & $<4$ \\
\hline
\end{tabular}

(c) Nutrient status

\begin{tabular}{lll}
\hline Status & Organic matter $(\%)$ & Olsen $\mathbf{P}(\mathbf{m g} / \mathbf{k g}$ soil $)$ \\
\hline Poor & $<0.86$ & $0-8$ \\
Satisfactory & $0.86-1.29$ & $8-15$ \\
Adequate & $>1.29$ & $>15$ \\
\hline
\end{tabular}

Source: Malik et al 1984.

\section{Results}

\subsection{Soil Texture}

The results (Table 2) showed that 91.18 percent soils in Layyah district were sandy loam and 8.53 percent soils were loam in texture. Heavy textured soils (clay loam) were noticed at few sites $(0.29 \%)$. In tehsil Layyah, 88.16 percent soils were sandy loam and 11.49 percent soils were loam. In tehsils Karor Lal Esan and Chaubara, 91.39 and 97.20 percent soils were sandy loam, respectively. In Karor Lal Esan, 8.16 percent soils were loam and 2.79 percent soils were loam in tehsil Chaubara. This shows that soils are quite heterogeneous and variable in texture. Rashid (1993) reported that the soils in Chakwal district were predominantly light textured as sandy loam and sandy clay loam were the dominant textured classes. The dissected old loess and alluvial terraces in the area have predominantly silt and silt loam texture, formed from parent material loess, residual material, old river alluvium and sub recent out wash. About $31 \%$ soils are sandy to sandy loam in texture and the remaining are highly eroded (Tager and Bhatti, 2001).

\subsection{Dissolved Salts (Electrical Conductivity)}

Dissolved salts in soils create hindrance in normal nutrient uptake process by imbalance of ions, antagonistic and osmotic effects. Normally for research purpose, electrical conductivity of soil extract (ECe) is used for total dissolved salts but for assessing soil salinity and sodicity for advisory purpose, a soil-water suspension of EC 1:10 is normally used as described in the manual of Malik et al. 1984. Various workers used the same method for electrical conductivity. However, EC1:10 is converted to ECe by multiplying with the factor Saturation percentage/100 as described by US Salinity Lab. Staff 1954. The data (Table 3) showed that 
99.42 percent of soil samples analysed in district Layyah were free from salinity/sodicity. All tehsils showed similar trend i.e. $>99$ percent soils had total dissolved salts in normal range except a few sites $(0.68 \%)$ which were sodic in nature. The reason for low accumulation of salts in soils is that texture of the most of soils is sandy loam to loam and high and sporadic rainfall in monsoon season leaches/washes the salts, if any, from the root zone. These results are in line with the findings of Rehman et al. (2000) and Mahmood et al. (1998).

Table 2. Status of Soil Texture of District Layyah during 2008-2013

\begin{tabular}{llll}
\hline \multirow{2}{*}{ Name of Tehsil } & Texture & & \\
\cline { 2 - 4 } & Light & Medium & Heavy \\
\hline Layyah & $88.16 \%$ & $11.49 \%$ & $0.34 \%$ \\
Karor Lal Eisen & $91.39 \%$ & $8.16 \%$ & $0.43 \%$ \\
Chaubara & $97.20 \%$ & $2.79 \%$ & $0.00 \%$ \\
Overall Layyah District & 91.18 & $8.53 \%$ & $0.28 \%$ \\
\hline
\end{tabular}

Table 3. Status of Soil Salinity/Sidicity of District Layyah during 2008-2013.

\begin{tabular}{lllll}
\hline \multirow{2}{*}{ Name of Tehsil } & \multicolumn{2}{l}{ EC $(\mathbf{d S} / \mathbf{m})$} & & $\mathbf{p H}$ \\
\cline { 2 - 5 } & $<\mathbf{4}$ & $\mathbf{4}$ & $<\mathbf{8 . 5}$ & $<\mathbf{8 . 5}$ \\
\hline Layyah & $99.49 \%$ & $0.51 \%$ & $87.60 \%$ & $10.48 \%$ \\
Karor Lal Eisen & $99.09 \%$ & $0.90 \%$ & $91.28 \%$ & $8.71 \%$ \\
Chaubara & $99.59 \%$ & $0.78 \%$ & $87.29 \%$ & $12.70 \%$ \\
Overall Layyah District & $99.42 \%$ & $0.68 \%$ & $88.43 \%$ & $11.59 \%$ \\
\hline
\end{tabular}

\subsection{Soil Reaction (pH)}

The results (Table 3) further revealed that 88.43 percent soils at district level had $\mathrm{pH}<8.5$. These soils are also good for agriculture but $\mathrm{pH}$ towards higher side (i.e. >8.2) has some limitations for high value crops. Soils having $\mathrm{pH}>8.5$ need special attention and some suitable amendment (acid or gypsum) is to be applied for their reclamation according to the soil gypsum requirement. Such soils in Layyah district are very few $(11.59 \%)$. As the $\mathrm{pH}$ of soils is alkaline due to the indigenous parent material, calcareousness and low organic matter, this situation is similar in almost all soils. Latif et al. (2008) also reported pH of Chakwal soils in alkaline range of 7.7-7.8. When the average values are taken in to consideration, the area looks free from salinity/sodicity menace.

\subsection{Organic Matter}

Nitrogen requirements are usually recommended by the Soil Testing Laboratories, based on the estimation of nitrogen released by the SOM contents (Cooke, 1982). Higher organic matter reflects the higher crops yield. The data (Table 4) showed that 94.20 percent soils in Layyah district were poor and only 0.55 percent were adequate with respect to organic matter. Soils in tehsil Layyah were found deficient (92.81\%) in organic matter while 0.87 percent soils in tehsil Layyah were satisfactory in organic matter. The reason for low organic matter in these tehsils is that temperature in summer exceeds $50{ }^{\circ} \mathrm{C}$ due to which its decomposition rate is increased. Also farmers generally do not use farmyard manure and remove crops totally (grain plus straw) from soils leaving it fallow. The trend of green manuring is also not observed. Rashid (1994) reported that OM contents ranged from $0.2-1.3 \%$ in surface soils of Chakwal. The soils of Pakistan are quite low in organic matter. Generally the soils in Punjab contained less than $1 \%$ organic carbon (Azam, 1988). The decline in SOM is due to crops grown without or very meager addition of plant and animal manners. When the OM level declined to $40-60 \%$ of their original level, the soil productivity was affected, erosion loses of soil surface increased and net mineralization of soil fell below the level required for sustained grain crop production (Doran and Smith, 1987).

Table 4. Status of Organic Matter of District Layyah during 2008-2013

\begin{tabular}{llll}
\hline \multirow{2}{*}{ Name of Tehsil } & \multicolumn{3}{l}{ Organic Matter } \\
\cline { 2 - 4 } & Poor & Medium & Adequate \\
\hline Layyah & $92.81 \%$ & $6.31 \%$ & $0.87 \%$ \\
Karor Lal Eisen & $91.96 \%$ & $7.64 \%$ & $0.39 \%$ \\
Chaubara & $99.35 \%$ & $0.64 \%$ & $0.00 \%$ \\
Overall Layyah District & $94.20 \%$ & $5.25 \%$ & $0.55 \%$ \\
\hline
\end{tabular}

\subsection{Available Phosphorus}

With regards to phosphorus availability to plants, the results (Table 4) showed that 67.75 percent soils of Layyah district were poor in this nutrient. All tehsils had similar trend and were quite deficient in available phosphorus. The reasons for poor available phosphorus is that farmers do not apply phosphatic fertilizers to crops according to recommendations and only nitrogenous fertilizers are applied due to price hike of phosphatic fertilizers. Malik et al. (1984) and Rashid (1994) reported that $75-95 \%$ soils in Punjab are deficient in P. They also indicated that $61 \%$ soils contained up to $3 \mathrm{mg} \mathrm{kg}^{-1}$ and $34 \%$ soils had $3-12 \mathrm{mg} \mathrm{kg}^{-1} \mathrm{P}$ contents.

Table 5. Status of Available Phosphorus of District Layyah during 20082013

\begin{tabular}{llll}
\hline \multirow{2}{*}{ Name of Tehsil } & \multicolumn{3}{l}{ Available Phosphorus } \\
\cline { 2 - 4 } & Poor & Medium & Adequate \\
\hline Layyah & $64.56 \%$ & $29.95 \%$ & $8.47 \%$ \\
Karor Lal Eisen & $62.99 \%$ & $29.05 \%$ & $7.94 \%$ \\
Chaubara & $79.10 \%$ & $16.86 \%$ & $4.03 \%$ \\
Overall Layyah District & $67.75 \%$ & $25.00 \%$ & $7.25 \%$ \\
\hline
\end{tabular}

\section{Discussions and Recommendation}

Soil organic matter level and soil fertility status may be increased by green manuring (sesbania, guar, etc.) once in three years. With this practice, the sufficient moisture can be preserved for rabi crops (wheat, canola, etc). Inorganic fertilizers (NPK) should be applied in balanced form according to soil test value and their use efficiency can be increased by band placement for row-sown crops. The low nutrient concentrations might be due to losses through leaching, as these soils were found sandy in nature or due to low soil organic matter because of rapid decomposition at some locations. Farmers from all over the Punjab province can get the fertilizer recommendation for different crops from the website http://www.fertilizeruaf.pk.General 
recommendations for the farmers of district Layyah on the basis of results are given in Annexure 1.
The author would like to acknowledge the District Government Layyah for providing laboratory facility for analyses purposes to complete this study.

\section{Acknowledgements}

Annexure 1. Nutrients recommendations for different crops in district Layyah

\begin{tabular}{|c|c|c|c|c|c|c|c|c|}
\hline \multirow{2}{*}{ Sr. No } & \multirow{2}{*}{ Name of Crops } & \multirow{2}{*}{$\begin{array}{l}\text { Soil Status/Variety Sown/Specific } \\
\text { Condition }\end{array}$} & \multicolumn{3}{|c|}{ Nutrients kg/ha } & \multicolumn{3}{|l|}{ Bags/Acre } \\
\hline & & & $\mathbf{N}$ & $\mathrm{P}_{2} \mathrm{O}_{5}$ & $\mathrm{~K}_{2} \mathrm{O}$ & Urea & DAP & SOP \\
\hline \multirow{3}{*}{1} & \multirow{3}{*}{ Wheat(irrigated) } & Poor Soil & 128 & 114 & 62 & 1.50 & 2.00 & 1.00 \\
\hline & & Medium Soil & 104 & 84 & 62 & 1.50 & 1.50 & 1.00 \\
\hline & & Fertile Soil & 79 & 57 & 62 & 1.00 & 1.00 & 1.00 \\
\hline \multirow{2}{*}{2} & \multirow{3}{*}{ Cotton (BT) } & Early Sowing(Feb-March) & $341-398$ & 114 & $91-124$ & $6.00-7.00$ & 2.00 & $1.50-2.00$ \\
\hline & & Late Sowing(Apr-May) & $200-227$ & 86 & 91 & $3.50-4.00$ & 1.50 & 1.50 \\
\hline \multirow{3}{*}{3} & & Poor Soil & 296 & 170 & 124 & 5.25 & 3.00 & 2.00 \\
\hline & \multirow[t]{2}{*}{ Sugarcane } & Medium Soil & 227 & 114 & 124 & 4.00 & 2.00 & 2.00 \\
\hline & & Fertile Soil & 170 & 57 & 61 & 3.00 & 1.00 & 1.00 \\
\hline \multirow{2}{*}{4} & \multirow{2}{*}{ Rice } & Fine varieties & 170 & 101 & 79 & 3.00 & 1.75 as TSP & 1.25 \\
\hline & & Basmati Varieties & 141 & 101 & 79 & 2.50 & 1.75 as TSP & 1.25 \\
\hline \multirow{2}{*}{5} & \multirow{2}{*}{ Maize(Irrigated) } & Poor Soil & 227 & 141 & 91 & 3.00 & 2.50 & 1.50 \\
\hline & & Medium Soil & 168 & 114 & 62 & 2.25 & 2.00 & 1.00 \\
\hline 6 & Gram & For Tehsil Chaubara & 32 & 84 & --- & 0.50 & 1.50 as TSP & --- \\
\hline 7 & Water Melon & For Tehsil Layyah & 158 & 203 & 62 & 2.00 & $\begin{array}{l}2.00 \text { as DAP \& } \\
4.00 \text { as SSP }\end{array}$ & 1.00 \\
\hline
\end{tabular}

Source: Rapid Soil Fertility Survey and Soil Testing Institute, Punjab, Lahore (2012).

Annexure 2. Nutrients recommendations for Citrus orchard in district Layyah.

\begin{tabular}{|c|c|c|c|c|c|}
\hline \multirow{2}{*}{ Age of plant } & FYM & $\mathbf{N}$ & $\mathbf{P}$ & $\mathbf{K}$ & Zinc \\
\hline & (kg/plant/year) & \multicolumn{4}{|c|}{ (g/plant/ year) } \\
\hline At plantation & 20 & 0 & 0 & 0 & 0 \\
\hline 1 year & 0 & 0 & 0 & 0 & 0 \\
\hline 2 years & 10 & 125 & 0 & 0 & 0 \\
\hline 3 years & 15 & 250 & 125 & 0 & 0 \\
\hline 4 years & 20 & 500 & 250 & 0 & 0 \\
\hline $5-9$ years & 40 & 1000 & 500 & 500 & 50 \\
\hline$>10$ years & 60 & 1500 & 750 & 500 & 50 \\
\hline
\end{tabular}

Source: NFDC, (2003).

Annexure 3. Area, Production and Average Yield of Major Crops of district Layyah (2008-14).

\begin{tabular}{|c|c|c|c|c|c|c|c|}
\hline Name of crop & Area/Production/ average yield & 2008-09 & 2009-10 & 2010-11 & 2011-12 & 2012-13 & 2013-14 \\
\hline \multirow{3}{*}{ Wheat } & Area (000 Acre) & 491 & 498 & 485 & 471 & 480 & 488 \\
\hline & Production (000 Tons) & 503.86 & 515.36 & 557.55 & 527.40 & 519.56 & 610.512 \\
\hline & Average Yield (Mounds) & 27.49 & 27.73 & 30.80 & 30.00 & 29.00 & 33.50 \\
\hline \multirow{3}{*}{ Suger Cane } & Area (000 Acre) & 32 & 29 & 22 & 30 & 31 & 35 \\
\hline & Production (000 Tons) & 648.55 & 623.47 & 648.05 & 650.57 & 676.88 & 770.75 \\
\hline & Average Yield (Mounds) & 543 & 576 & 570 & 581 & 585 & 590 \\
\hline \multirow{2}{*}{ Gram } & Area $(000$ Acre $)$ & 275.52 & 263.04 & 270.00 & 255.18 & 255.21 & 255.66 \\
\hline & Average Yield (Mounds) & - & - & 4.56 & - & 6.96 & 5.02 \\
\hline
\end{tabular}

Source: Statistics Department, Layyah Punjab Pakistan (2014).

[2] Anon. 2003. Fertilizers and their Use in Pakistan. Training Bulletin. 3rd Ed. NFDC, Islamabad.

\section{References}

[1] Ahmed, N. and M. Rashid. 2003. Fertilizer Use in Pakistan. NFDC. Planning and Development division, Islamabad. 141p.
[3] Anon. 1954. Diagnosis and Improvement of Saline and Alkali Soils. USDA Handbook No. 60, U. S. Salinity Lab. Staff. Washington, DC, USA. p. 16-17. 
[4] Cooke, G.W.1982. An introduction to soil analysis. World Crops 1: 8-9.

[5] Doran, J.W. and M.S. Smith. 1987. Organic matter management and utilization of soil and fertilizer nutrients. $p$ 53-71. In: Soil Fertility and Organic Matter as Critical Components of Production System. J.J. Mortvedt and D.R. Buxton (eds). Soil Science Society of America, WI, USA.

[6] FAO. "Land Resources Evaluation and The Role of Landrelated Indicators, by W.G. Sombroek", Land Quality Indicators and Their Use in Sustainable Agriculture and Rural Development, land and water bulletin, 5. Rome, [1997].

[7] FAO. "A Frame work for Land Evaluation", Soils Bulletin, 32. Rome, [1993].

[8] J. Ryan., "Soil Fertility Enhancement in Mediterranean-type Dryland Agriculture: A Prerequisite for Development. In Challenges and Strategies of Dryland Agriculture", Crop Science Society of America and American Society of Agronomy [2004].

[9] Latif, R., S. Ali and R. Hayat. 2008. Nitrogen fixation and yield of peanut affected by inorganic fertilizers, variety and inoculums interaction in rainfed areas of Punjab. Soil and Environment 27(1): 77-83.

[10] Mahmood, T., H. Mahmood, M. R. Raja and K. H. Gill. 1998. Soil fertility status of Rawalpindi district. Pak. J. Soil Sci. 14 (1-2): 66-69.

[11] Malik, D. M., M. A. Khan and T. A. Chaudhry. 1984. Analysis Manual for Soils, Plants and Waters. Rapid Soil Fertility Survey and Soil Testing Institute, Lahore, Pakistan.

[12] Motsara, M.R. 2002. Available nitrogen, phosphorus and potassium status of Indian soils as depicted by soil fertility maps. Fertilizer News 47(8):15-21.
[13] Nelson, S.W. and I.E. Sommers. 1982. Total carbon, organic carbon and organic matter. P. 539-80. In: Methods of Soil Analysis. Chemical and Microbial Properties. Agron. No. 9. Part 2, 2nd Ed. A.L. Page (ed.). American Society of Agronomy, Madison, Wisconsin, USA.

[14] Olsen, S.O. and I.E. Sommers. 1982. Phosphorus. p. 403-430. In: Methods of Soil Analysis. A.L.Page (ed.). Chemical and Microbial Properties. Part 2, 2nd Ed. American Society of Agronomy, Madison, Wisconsin, USA.

[15] Rafiq, M. 1996. Soil resources of Pakistan. p. 439-469. In: Soil Science. E. Bashir and R. Bantel (eds.). National Book Foundation. Islamabad, Pakistan.

[16] Rashid, A. 1994. Nutrient Indexing Surveys and Micronutrient Requirement of Crops. NARC, Islamabad.

[17] Rashid, A. 1993. Nutrient disorders of rapeseed-mutard and wheat grown in Potohar area. Micronutrient Project. Annual Report 1991-92. NARC, Islamabad.

[18] Rehman, O., A. A. Sheikh and K. H. Gill. 2000. Available phosphorus and $\mathrm{pH}$ status of Attock soils. Pak. J. Agri. Sci. 37 (1-2): 74-76.

[19] Schofield, R.K. and A.W. Taylor. 1955. The measurement of soil pH. Soil Science Society of America Proceeding 19: 164167.

[20] Soil Salinity Lab. Staff. 1954. Diagnosis and Improvement of Saline and Alkali Soils. USDA Hand book 60, Washington, D.C., USA.

[21] Tager, S. and A. Bhatti. 2001. Physical properties of soil. p. 113-144. In: Soil Science. E. Bashir and R. Bantel (eds.). National Book Foundation, Islamabad, Pakistan. 